\title{
The role of interpolated stimuli in the retroactive interference of pigeon short-term memory
}

\author{
DONALD F. KENDRICK \\ Middle Tennessee State University, Murfreesboro, Tennessee \\ and \\ MARK RILLING \\ Michigan State University, East Lansing, Michigan
}

\begin{abstract}
Theoretical accounts of retroactive interference in delayed matching-to-sample attribute decrements in performance to disruption of rehearsal or retrieval of a sample stimulus representation or an instruction of which test stimulus to peck. However, only two sources of retroactive interference have been identified so far: changes in illumination and electric shock. The present experiments sought evidence of additional sources of retroactive interference. Stimuli associated with variable interval (VI), extinction (EXT), and differential reinforcement of other behavior (DRO) schedules were interpolated into the delays of delayed matching. The results of three experiments demonstrated that a stimulus associated with a VI schedule of reinforcement interferes with delayed matching but that an EXT-associated stimulus does not. Experiment 2 showed that a DRO-associated stimulus interferes with delayed matching. Additional analysis indicated that interference with delayed matching was a function of the degree to which the interpolated stimuli disrupted delay-interval behavior associated with accurate matching. These findings support the behavioral-context hypothesis, which states that response-produced stimuli arising from delay behavior provide the context necessary for accurate matching. Retroactive interference thus occurs to the extent that interpolated stimuli interfere with baseline delay behavior.
\end{abstract}

Short-term memory in animals has been extensively studied in the delayed matching-to-sample paradigm. The successive delayed matching procedure is composed of four successive events: presentation of the sample stimulus, a delay interval, presentation of the test stimulus, and an intertrial interval. Responses during the test stimulus are correct or incorrect, that is, reinforced or not, conditional upon the relation between the previously presented sample stimulus and the current test stimulus (Wasserman, 1976). The task for the animal is to remember at the time of the test stimulus information based on the sample stimulus.

Retroactive interference may be produced by interpolating events into the delay period. Retroactive interference is observed when matching accuracy on the interpolated test trials declines relative to matching accuracy on the baseline trials (Grant \& Roberts, 1976; Medin, Reynolds, \& Parkinson, 1980; Moise, 1970; Wright, Urcuioli, Sands, \& Santiago, 1981).

This research was supported by Grant BNS 81-10966 from the National Science Foundation to Mark Rilling. Requests for reprints may be addressed to either the first or the second author. Donald F. Kendrick's address is: Department of Psychology, Middle Tennessee State University, P.O. Box 474, Murfreesboro, TN 37132. Mark Rilling's is: Department of Psychology, Michigan State University, East Lansing, MI 48824.
In pigeons, change in illumination is the primary source of retroactive interference (Cook, 1980; Grant \& Roberts, 1976; Roberts \& Grant, 1978; Tranberg \& Rilling, 1980). Similarity of the interpolated stimuli to the sample and test stimuli, and saliency, familiarity, and complexity of the interpolated stimuli are not significant sources of retroactive interference (Grant \& Roberts, 1976; Medin et al., 1980; Wright et al., 1981). Both ambient illumination and localized keylight illumination interpolated into the delay interval of delayed matching interfere with matching accuracy (Grant \& Roberts, 1976). Additionally, increases in illumination decrease the accuracy of matching in direct proportion (Roberts \& Grant, 1978). Moreover, Tranberg and Rilling (1980) demonstrated that both increases and decreases in illumination relative to baseline illumination levels interfere with delayed matching (also see Cook, 1980)

These resuls suggest that the reduction in matching accuracy is due to interference with rehearsal. According to the rehearsal interpretation, illumination changes divert attention from the active maintenance of information necessary for accurate matching (Roberts \& Grant, 1978). Disruption of rehearsal may occur because the visual memory trace is degraded by illumination changes (Roberts \& Grant, 1978) or because short-term memory is of limited capacity (Wagner, 1978) and illumination 
changes displace the sample representation. Cook (1980) suggests that the novelty of illumination changes interferes with rehearsal. However, Wilkie, Summers, and Spetch (1981) found that retroactive interference in pigeons was modality-specific; houselight illumination interfered with matching, but sound and vibration did not. Therefore novelty of interpolated stimuli cannot be the sole source of retroactive interference. Trace theory and limited capacity are the two more likely explanations.

A third possibility is behavioral. There is evidence that disruption of delay behavior is a significant source of retroactive interference in animals and humans (Anderson \& Craik, 1974; Kendrick, Rilling, \& Stonebraker, 1981; Kulp, 1967; Moise, 1970; Murdock, 1967; Posner \& Konick, 1966; Pylyshyn, 1965; Thompson, Van Hemel, Winston, \& Pappas, 1983; Tranberg \& Rilling, 1980; Williams, Beaver, Spence, \& Rundell, 1969). For example, Moise (1970) found that the matching accuracy of monkeys was directly correlated with the number of responses on a reaction-time task interpolated into the delay intervals. Thompson et al. (1983) found that illumination and shock interfered with delayed matching and produced disruption of baseline delay-interval behavior. Also, white noise produced little interference with matching accuracy and little disruption of delay behavior.

The correlation between disrupted matching performance and disrupted delay behavior may reflect the operation of overt behavioral mediation of matching (Blough, 1959; Urcuioli \& Honig, 1980; Zentall, Hogan, Howard, \& Moore, 1978). Disruption of sample-specific mediating behavior would be an obvious source of interference with delayed matching. The problem with this position is that many birds simply do not exhibit sample-specific delay behavior, and yet match accurately and exhibit interference effects. Several studies have demonstrated poor matching and changes in delay behavior with no observable sample-specific behaviors (Kendrick et al., 1981; Moise, 1970; Stonebraker, Rilling, \& Kendrick, 1981; Tranberg \& Rilling, 1980). Thompson et al. (1983), suggested that rehearsal might be a dual process: an overt behavioral process in which sample stimuli elicit samplespecific behavior correlated with an "instruction" to peck or not to peck and a covert rehearsal process in which information concerning which test stimuli to peck at or not to peck at is maintained during the delays.

Alternatively, Kendrick et al. (1981) argued that baseline delay behavior generated response-produced stimuli that served as the context in which test stimuli effect retrieval of sample representations. This retrieval position does not necessarily deny rehearsal in animals, but proposes a secondary mechanism that operates when sample information has not been rehearsed. Disruption of delay behavior thus alters the behavioral context necessary for successful retrieval of sample stimulus information. In the present context, disruption of delay behavior may disrupt rehearsal and alter the behavioral context neces- sary for retrieval. By either account, that of Kendrick et al. or that of Thompson et al., disruption of baseline delay behavior is a critical source of retroactive interference in animal short-term memory.

The purpose of the present study was to further the analysis of the behavioral-disruption hypothesis by interpolating stimuli associated with a variable-interval schedule of reinforcement (VI), differential reinforcement of other behavior schedule (DRO), and an extinction schedule (EXT) into the delay intervals of delayed matching. If retroactive interference of pigeon short-term memory is due to disruption of delay behavior, the VI-, DRO- and EXT-associated stimuli should interfere with delayed matching to the degree that they interfere with baseline delay behavior.

\section{EXPERIMENT 1}

The purpose of Experiment 1 was first to determine whether VI- and EXT-associated stimuli differentially interfered with delayed matching when interpolated into the delays. It was possible that neither or both interfered. Previous research had interpolated stimuli that either unconditionally elicited responses (e.g., illumination and shock) or that had not been associated with reinforced behavior (e.g., keylight illumination). The only stimuli known to produce interference in pigeon short-term memory were unconditioned stimuli. It was thus necessary to determine whether conditioned stimuli could also produce retroactive interference. Secondly, interpolated stimuli alter delay illumination levels, a known source of interference. Both stimuli could thus interfere with matching accuracy by increasing illumination levels, perhaps masking any differential effects due to their specific association with reinforced keypecking and extinction.

Pigeons were first trained on a delayed matching-tosample task in which the sample stimuli were food versus no food, and the test stimuli, red and green keylights, were presented on the right key. Then (in sessions that alternated with delayed matching training) the pigeons were trained to peck the left key on a multiple schedule of reinforcement with a variable interval and an extinction component (MULT VI EXT). The right key controlled the matching task, and the left key controlled the multiple schedule. Following acquisition of delayed matching, the stimulus associated with the VI schedule and the stimulus associated with the EXT schedule were interpolated by illumination of the left key for the first time during the delay interval of delayed matching. The question of interest was whether the bird would peck the left key when the stimulus controlling the VI schedule was presented or would remain attentive to the matching task as evidenced by its pecking the right key during the delay interval. The EXT-associated stimulus served as a control for disruption due to illumination changes resulting from the turning on of the keylights. 
Two features of the procedure require emphasis. First, food and no food (i.e., the houselight was turned off for $2.5 \mathrm{sec})$ vere the sample stimuli in delayed matching (Maki, 1979; Maki \& Hegvik, 1980). Thus, the effective sample stimulus may have been food and light off, light on and light off, or any such combination. Relative to color keylight sample stimuli, food and no food allow the longer delay intervals necessary for the pigeons to fully engage in the VI task. ((Color stimuli were the samples in Experiment 3.) Second, a successive matching task was presented on the rightmost response key, and the VI and EXT stimuli were presented on the leftmost response key.

\section{Method}

\section{Subjects}

Two experimentally naive White Carneaux pigeons, maintained at $80 \% \pm 20 \mathrm{~g}$ of their ad-lib weights, served as subjects. The birds were individually housed in a temperature-controlled colony room under constant illumination. Grit and water were available ad lib and mixed grain was fed as necessary to maintain criterial weight.

\section{Apparatus}

A two-key Lehigh Valley Electronics pigeon chamber was used. The 2.54-cm-diam plastic response keys required a force of $15 \mathrm{~g}$ $(.15 \mathrm{~N})$ for activation. The two keys were positioned $13.54 \mathrm{~cm}$ apart and were $9 \mathrm{~cm}$ from the top of the chamber, $8 \mathrm{~cm}$ from the sides, and $25.5 \mathrm{~cm}$ from the floor. The houselight $(28 \mathrm{~V} \mathrm{dc}, \mathrm{GE757})$ was centered above the two response keys, $2.5 \mathrm{~cm}$ from the top of the chamber. The grain magazine was $5 \times 5 \mathrm{~cm}, 11.5 \mathrm{~cm}$ from the floor and centered between the two response keys. The keys were transilluminated by a display projector (IEE Series $10,28 \mathrm{~V} \mathrm{dc}$, GE757). The walls of the chamber were white matte with an unpainted aluminum stimulus panel. Masking noise was provided by a small ventilation fan. Electromechanical programming equipment controlled the stimulus events, recorded the data, and was located in an adjoining room.

\section{Procedure}

There were four primary stages to this experiment: pretraining, acquisition of delayed matching-to-sample (DMTS), acquisition of the MULT VI EXT discrimination alternating with maintenance of delayed matching, and the probe testing stage. In all stages, reinforcement was 2.5 -sec access to mixed grain, and the sessions were approximately $1 \mathrm{~h}$ daily, 5-6 days per week.

Pretraining. Both pigeons were habituated to the operant chamber and magazine trained. Thirty magazine training trials were given, and both birds were approaching and eating reliably at the conclusion of the session. Autoshaping to red and green keylight stimuli on the right response key took place the following session. One session of 60 trials was required to establish reliable responding. Stimulus durations were $6 \mathrm{sec}$ and were pseudorandomly arranged such that the same color did not appear more than three times successively and each occurred an equal number of times. A variable intertrial interval (ITI) with a mean value of $60 \mathrm{sec}$ was used.

Acquisition of delayed matching-to-sample. After autoshaping, acquisition of symbolic successive DMTS began. Sample stimuli, 2.5 -sec access to mixed grain or $2.5 \mathrm{sec}$ of darkness (houselight extinguished), followed a $30-\mathrm{sec}$ ITI. When the sample stimulus was food, the hopper remained in the raised position, the enclosure illuminated, until the pigeon approached and began eating. The 2.5$\mathrm{sec}$ timer was activated when the pigeon broke a photobeam within the magazine enclosure. The no-food sample stimulus $(2.5 \mathrm{sec}$ of darkness) was automatically initiated at the beginning of the trial.
A delay of $1 \mathrm{sec}$ followed the sample stimuli, after which the rightmost response key was transilluminated with either a red or a green test stimulus. Test stimuli were a minimum of $6 \mathrm{sec}$, after which, on positive trials, a single peck produced reinforcement; on negative trials, the ITI was initiated automatically at the end of the $6 \mathrm{sec}$. Positive trials were food-green (FG + ) and no-food-red (NFR+); negative trials were food-red (FR-) and no-food-green (NFG-).

The four trial types, FG +, NFR +, FR -, NFG - , were pseudorandomly presented such that the same trial did not appear more than two times in succession and each occurred an equal number of times per session. A different pseudorandom order of trials was used each session. There were 80 trials per session, 20 of each trial type. The 1 -sec delays were incremented by 1 sec when $80 \%$ or more of the total responses of a session were during the positive test stimuli. Both birds were thus advanced to 10 -sec delay intervals. Because of the complex nature of the ensuing training and testing conditions, both birds were reduced to 8-sec delay intervals at which they were maintained for the remainder of the experiment. The leftmost key was dark during this phase.

MULT VI EXT and DMTS maintenance. DMTS was maintained on even-numbered sessions; MULT VI EXT discrimination training was presented on odd-numbered sessions. DMTS comparison stimuli were always presented on the right response key, and the MULT VI EXT discrimination was always presented on the left response key. Initially, the birds were autoshaped to peck the VI stimulus: three small white dots were oriented vertically on a black surround. They were then placed on a VI $15-\mathrm{sec}$, VI $30-\mathrm{sec}$, VI 45-sec, and finally a VI 60-sec schedule of reinforcement, each in effect for one session. Next, the birds were placed on a multiple schedule variable-interval 30-sec extinction (MULT VI EXT). The EXT stimulus was three white horizontal bars, $2.54 \mathrm{~cm}$ long, on a black surround. Each stimulus lasted $10 \mathrm{sec}$ with a 5 -sec interstimulus interval (ISI). There were approximately 100 presentations of each stimulus per session. When more than $90 \%$ of the responses were to the VI stimulus for 10 successive sessions and DMTS performance was maintained at or above $80 \%$ for 10 sessions of the same period, the next phase was begun.

Probe testing. In this phase, the MULT VI EXT discrimination was terminated and 5 consecutive days of baseline DMTS was initiated, after which testing began. Ten test sessions were conducted. A test session consisted of 80 DMTS trials, 20 baseline trials in which no stimuli were presented on the left key during the 8-sec delay interval, 20 VI trials in which the leftmost response key was illuminated with the VI stimulus during the 8-sec delay intervals (no reinforcement was available), 20 VI trials in which responding was reinforced, and 20 EXT trials in which the leftmost response key was illuminated with the EXT stimulus during the 8-sec delay intervals. These four delay-interval conditions were pseudorandomly arranged such that no more than two of the same type could occur consecutively. There were five of each DMTS trial type, FG +, $\mathrm{NFR}+, \mathrm{FR}-, \mathrm{NFG}-$, to comprise the 20 trials per condition, and stimulus durations were those used in acquisition and baseline maintenance.

Responses during the delay intervals were recorded from the right response key (the DMTS key) during all delay interval conditions: baseline, VI without reinforcement, VI with reinforcement, and EXT. Responses to the left response key (with the interpolated stimuli) were recorded during the delay intervals when the VI- and EXT-associated stimuli were presented. Responses during these delay intervals were separately recorded after food and no-food sample stimuli. The response-rate data during the trials with reinforcement for VI responding were excluded from analysis because of periodic failure of the electromechanical unit responsible for counting responses during these trials. All other counters worked reliably.

The major independent variable was the rate of responding to the test stimuli as a function of the three test trial types: baseline, VI, and EXT. The rate of responding to the test stimuli was con- 
verted to a discrimination ratio calculated as the number of responses on positive trials divided by the number of responses on the positive and negative trials multiplied by 100 . Thus, a ratio of $100 \%$ indicates no responding on negative trials, and a $50 \%$ ratio indicates equal rates of responding on positive and negative trials.

\section{Results}

\section{Acquisition}

Discrimination performance on the MULT VI EXT schedule was established rapidly. The birds responded at relatively high rates during the VI component and at lower rates during the EXT component. Bird 5123 responded at $51.0 \mathrm{pecks} / \mathrm{min}$ during the VI component and at 1.7 pecks/min during the EXT component. Bird 445 responded at a mean rate of 60.0 pecks $/ \mathrm{min}$ in the VI component and at 1.2 pecks/min during EXT.

Performance on the DMTS task was maintained above $80 \%$; Bird 5123 achieved a discrimination ratio of $81.9 \%$ and Bird 445 achieved a ratio of $85.0 \%$. Sample-specific rates of responding during delays were observed for Bird 5123-46.4 pecks $/ \mathrm{min}$ after food samples and 62.6 pecks/min after no-food samples. This rate difference was correlated with overt behavior differences. Bird 5123 moved to the far corner of the operant chamber during the $2.5 \mathrm{sec}$ of darkness (no-food sample) and returned to the DMTS response key when the houselight came on at the beginning of the delay. The bird began pecking the DMTS response key immediately after food samples. Bird 445 did not exhibit sample-specific rates of responding during the delays; the rates were 1.2 pecks/min after food and $1.4 \mathrm{pecks} / \mathrm{min}$ after no food. Bird 445 also did not exhibit other forms of sample-specific behavior during the delays. This bird approached the DMTS response key af-

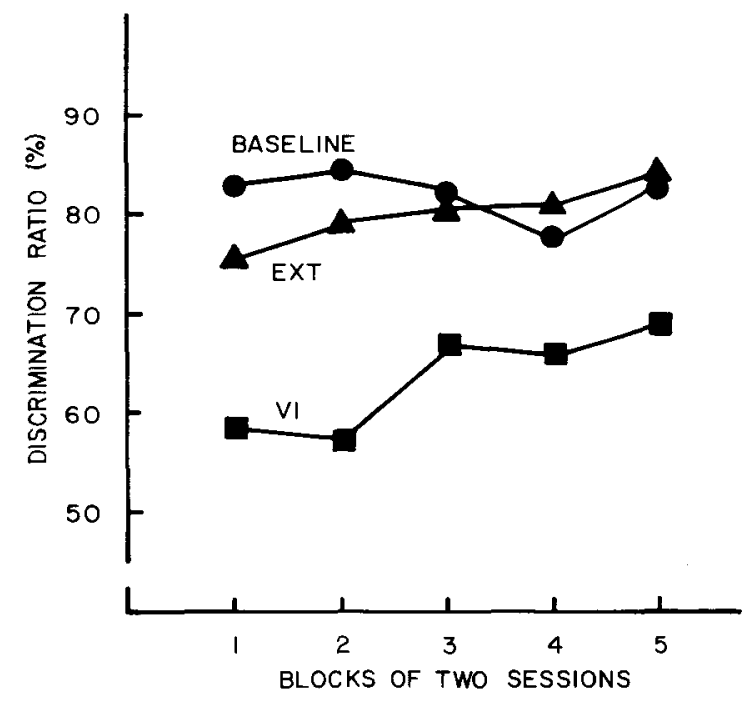

Figure 1. Matching accuracies across the 10 days of testing in which the delay intervals were blank (baseline), filled with the stimulus associated with an extinction schedule (EXT), or filled with a stimulus associated with a variable interval schedule (VI). Data from Experiment 1.
Table 1

Mean Response Rates per Minute During the Test Stimuli of the Delayed Matching Task in Experiment 1

\begin{tabular}{lcrrrr}
\hline & & \multicolumn{4}{c}{ Trial Type } \\
\cline { 3 - 6 } Subject & Stimulus & FR - & NFR + & FG + & NFG - \\
\hline \multirow{3}{*}{ B5123 } & None & 26 & 74 & 67 & 7 \\
& EXT & 24 & 71 & 65 & 7 \\
& VI & 35 & 52 & 57 & 32 \\
& None & 88 & 274 & 266 & 28 \\
B445 & EXT & 99 & 278 & 263 & 47 \\
& VI & 164 & 236 & 228 & 90 \\
\hline
\end{tabular}

Note-Food sample stimulus is denoted by $F$, the no-food sample by $N F$, red and green keylight stimuli by $R$ and $G$, respectively, and reinforced and nonreinforced trials by $(+)$ and $(-)$, respectively.

ter both samples, stood in front of the response key, and typically did not peck until onset of the test stimulus.

\section{Probe Testing}

Figure 1 shows the results of the probe tests plotted as the percentage discrimination ratio on the matching task as a function of the three conditions during the delays: baseline (both response keys dark during the delays), EXT (left response key illuminated with the EXT-associated stimulus, right response key dark), and VI (left response key illuminated with the VI-associated stimulus, right response key dark). Data from trials with a VI-scheduled reinforcer were excluded from analysis due to periodic failure of the counters responsible for recording keypecks during this event. As Figure 1 shows, the VI-associated stimulus interfered with matching accuracy, whereas the EXT-associated stimulus did not. An analysis of variance indicated a main effect of delay condition $[F(2,15)=$ $45.04, \mathrm{p}<.05]$. Dunnet's test revealed that the VIassociated stimulus reduced matching accuracy relative to the baseline $[\operatorname{tD}(3,15)=18.5, p<.05]$ and that the EXT-associated stimulus did not reduce matching accuracy relative to the baseline $[\operatorname{tD}(3,15)=1.6$, n.s. $]$.

Table 1 shows the mean rate of responding during the test stimuli of the matching task as a function of test condition. These data are averaged over the 10 sessions of testing. Generally, the VI-associated stimulus interfered with matching by increasing the rate of response during the negative trials and by lowering the rate during the positive trials. The EXT-associated stimulus did not much alter rates from baseline.

Both birds responded on the left response key during the VI-associated stimulus and did not respond on the left response key during the EXT-associated stimulus. Bird 5123 pecked the VI stimulus at a mean rate of 23 pecks/min following the food sample stimulus and at a mean rate of 55 pecks/min following the no-food sample stimulus. This is a statistically significant difference $[\mathrm{F}(1,19)=11.97, \mathrm{p}<.05]$. Bird 445 pecked the VIassociated stimulus at a mean rate of $71.7 \mathrm{pecks} / \mathrm{min}$ following the food sample stimulus and at a mean rate of $82.7 \mathrm{pecks} / \mathrm{min}$ following the no-food sample stimulus $[F(1,19)=2.24, p>.05]$. Baseline delay rates of 
Bird 5123 were 38.8 pecks/min after the food sample and 41.1 pecks $/ \mathrm{min}$ after the no-food sample $[\mathrm{F}(1,19)=1.00$, n.s.]. Bird 445 responded at a mean rate of 2.0 and 3.0 pecks $/ \mathrm{min}$ after food and no-food samples, respectively $[\mathrm{F}(1,19)=1.15$, n.s. $]$. Informal observation indicated no sample-specific delay behavior, except for Bird 5123, during the interpolated VI-associated stimulus, which paused longer after a food sample than after a no-food sample before pecking the VI-associated stimulus.

\section{Discussion}

The results of Experiment 1 demonstrate that a stimulus associated with a VI schedule of reinforcement retroactively interferes with matching and that a stimulus associated with extinction does not interfere. The two pigeons pecked the VI-associated stimulus during the delay on the matching task and exhibited reduced matching accuracy. The birds did not peck the EXT-associated stimulus during the delays, and matching accuracy remained high. The lack of sample-specific behavior during the baseline delays of testing argues against the possibility that the interpolated VI-associated stimulus reduced matching accuracy by interfering with samplespecific mediating behavior. However, it is clear that some component of the VI-associated stimulus is responsibleperhaps the high rate of keypecking it occasioned, or perhaps an expectancy for food aroused by the VIassociated stimulus (Delong \& Wasserman, 1981; Peterson \& Trapold, 1980).

\section{EXPERIMENT 2}

The purpose of Experiment 2 was twofold: (1) to examine the correlation between disruption of delay behavior and disruption of delayed matching, and (2) to determine if a DRO-associated stimulus retroactively interfered with delayed matching. A DRO-associated stimulus controls behavior other than keypecking. The advantage here is that we may compare the interfering effect of the VIassociated stimulus (a stimulus associated with food and high rates of keypecking) with a DRO-associated stimulus (a stimulus associated with food and little or no keypecking). Thus, we may determine if the high rate of keypecking occasioned by the VI-associated stimulus is a likely source of interference, whether a food-expectancy occasioned by interpolated stimuli is a likely source of interference, and whether disruption of baseline delay behavior is correlated with disrupted matching.

\section{Method}

\section{Subjects}

Three experimentally naive White Carneaux pigeons maintained under the same conditions listed in Experiment 1 served as subjects.

\section{Apparatus}

The apparatus was the same as in Experiment 1.

\section{Procedure}

The procedures of this experiment were similar to those of the first experiment. There were five stages: pretraining, MULT VI EXT DRO discrimination training, DMTS acquisition, DMTS baseline maintenance sessions alternated with MULT VI EXT DRO discrimination training sessions. Reinforcement was 2.5-sec access to mixed grain in all stages, and sessions lasted approximately $1 \mathrm{~h}$ daily, 5-6 days per week.

Pretraining. Habituation to the operant chamber and magazine training were the same as in Experiment 1. Autoshaping was the same as in Experiment 1, except the stimuli were the to-be VI stimulus, three small white dots oriented vertically on a black surround, and the to-be DRO stimulus, a small white triangle on a black surround. Each was equally probable, and each occurred an equal number of times per session. The birds were responding reliably within one or two sessions.

Discrimination training. Following autoshaping, a MULT VI EXT DRO schedule of reinforcement was initiated on the left response key. The EXT-associated stimulus was the same as in Experiment 1. Each stimulus was presented for $30 \mathrm{sec}$ with a 5-sec interstimulus interval (ISI). There were approximately 40 presentations of each stimulus per session. The VI component was a VI 15 -sec schedule for the first one or two sessions. By the end of the second session, all birds were responding reliably and were placed on a VI 30-sec schedule, which remained in effect throughout training. Reinforcers were delivered on the DRO schedule when a variable interval $35 \mathrm{sec}$ had timed out if no keypeck had occurred during the last $5 \mathrm{sec}$. The 5 -sec timer was reset by each keypeck during the timing; when no peck occurred, and the timer had time out, reinforcement was delivered and the variable-interval $35 \mathrm{sec}$ reinitiated. When more than $70 \%$ of responses were during the VIassociated stimulus and at least five sessions of discrimination training were completed, the next stage began.

DMTS acquisition and baseline. This stage was the same as in Experiment 1 except that delays were 5 rather than $8 \mathrm{sec}$. When steady-state matching was maintained for at least five consecutive sessions, the next stage began. Steady state required that $80 \%$ or more of the responses be to the matching test stimuli.

DMTS maintenance and MULT VI EXT DRO discrimination training. In this stage, the DMTS sessions alternated with the discrimination training sessions, as in Experiment 1. Five consecutive sessions of each task at or above criterial performance $(80 \%$ to the VI stimulus) was required before advancement to the next page.

Probe testing. In this stage, MULT VI EXT DRO discrimination training sessions alternated with DMTS test sessions. This differs from Experiment 1, in which probe testing sessions were conducted daily. The discrimination training was maintained as described earlier. The DMTS test sessions employed a probe procedure in which the VI-, EXT-, and DRO-associated stimuli were infrequently interpolated into the 5 -sec delay and were presented on the left response key (the key used in training the MULT VI EXT DRO discrimination). Of the 80 DMTS trials per session, 8 were probe trials and 72 were baseline trials. Thus, in any given test session, the same interpolated stimulus was presented on the left response key eight times. The four trial types, FR -, NFR + , FG + , NFG - , were thus probed twice each per test session. Reinforcers for pecking or not pecking the VI- and DRO-associated stimuli were not delivered during probe trials. Only one of the three interpolated stimuli was presented in any one test session, and there were three test sessions of each of the three interpolated stimuli. A Latin square was used to determine the order of test session types.

Responses were recorded during the following events: the ITI, baseline delays following food, baseline delays following no food, red and green test stimuli following food and no food on baseline trials, probe delays following food and no-food samples, and red and green test stimuli following food and no food on probe trials. Pecks to the left key during the probe trial delays (when the stimulus was interpolated on the left key) were also recorded. 


\section{Results}

\section{Acquisition}

All three birds acquired the MULT VI EXT DRO discrimination prior to testing. High rates of responding were obtained in the VI component relative to the EXT and DRO components. Response rates during the DRO component were lower than rates during the VI components, but were higher than rates during the EXT component, which were near zero. Bird 346 responded at 141.2, 0.2, and 17.2 pecks/min during the VI, EXT, and DRO schedules, respectively. Bird 5042 responded at 156.3, 0.2, and 67.4 pecks/min during the VI, EXT, and DRO schedules, respectively. Bird 375 responded at $349.1,0.6$, and 42.9 pecks/min during VI, EXT, and DRO schedules, respectively.

Baseline DMTS responding during the delays revealed sample-specific delay behavior. All three birds responded at higher rates following the no-food sample stimulus than after the food sample stimulus. Bird 346 responded at 58.6 pecks $/ \mathrm{min}$ after food and at $90.1 \mathrm{pecks} / \mathrm{min}$ after no food. Bird 5042 responded at $6.8 \mathrm{pecks} / \mathrm{min}$ after food and at $34.5 \mathrm{pecks} / \mathrm{min}$ after no food. Bird 375 pecked 60.5 times/min after food and 88.2 times/min after no food. All three birds moved to the matching key during the dark

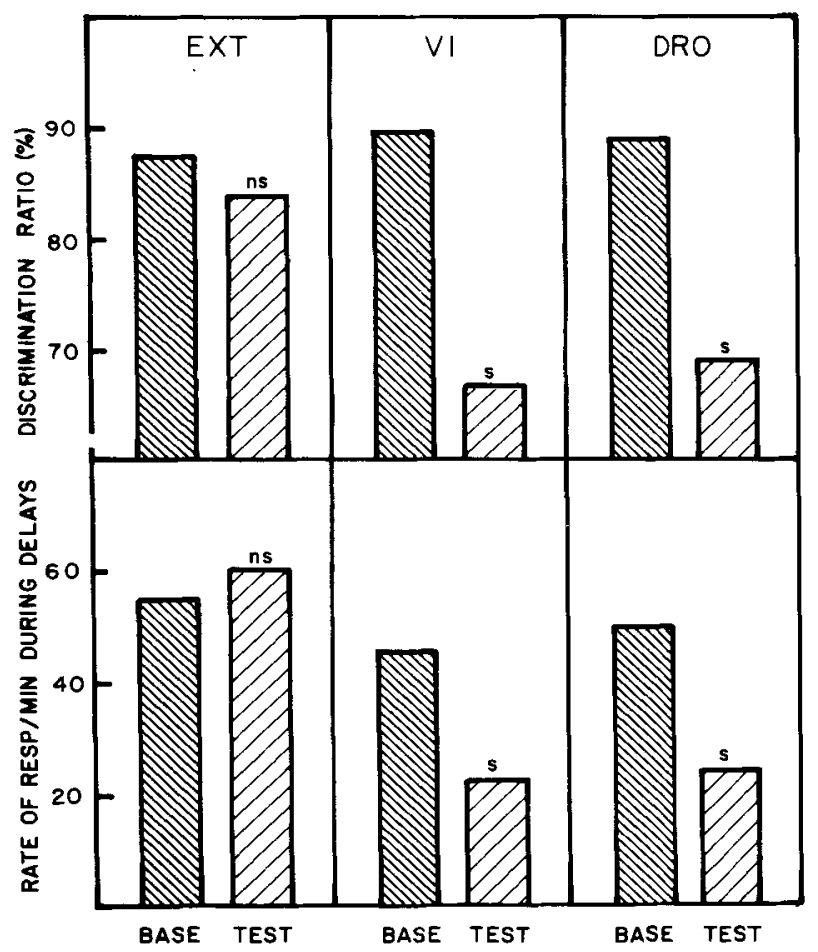

Figure 2. The top portion shows matching accuracies as a function of three test conditions: delays filled with stimuli associated with an extinction (EXT), variable interval schedule (VI), and a differential reinforcement of other behavior schedule (DRO). The bottom portion shows mean rates of responding during delay intervals as a function of the three test conditions. No stimuli were presented during baseline trials. These data are from Experiment 2. Nonsignificant (ns) and significant (s) differences from baseline are noted.
Table 2

Mean Response Rates per Minute During the Test Stimuli of the Delayed Matching Task in Experiment 2

\begin{tabular}{|c|c|c|c|c|c|c|c|}
\hline \multirow{2}{*}{ Subjects } & \multirow{2}{*}{$\begin{array}{l}\text { Delay } \\
\text { timulus }\end{array}$} & \multicolumn{4}{|c|}{ Trial Type } & \multirow{2}{*}{$\begin{array}{c}\text { Discrimination } \\
\text { Ratio }\end{array}$} & \multirow{2}{*}{$\begin{array}{c}\text { Delay } \\
\text { Keypecks }\end{array}$} \\
\hline & & FR- & NFR+ & FG+ & NFG- & & \\
\hline B346 & $\begin{array}{l}\text { None } \\
\text { EXT } \\
\text { VI } \\
\text { DRO }\end{array}$ & $\begin{array}{l}18 \\
62 \\
70 \\
32\end{array}$ & $\begin{array}{l}113 \\
132 \\
196 \\
136\end{array}$ & $\begin{array}{r}94 \\
134 \\
178 \\
112\end{array}$ & $\begin{array}{r}24 \\
88 \\
144 \\
84\end{array}$ & $\begin{array}{l}83 \% \\
64 \% \\
64 \% \\
68 \%\end{array}$ & $\begin{array}{l}57 \\
56 \\
18 \\
12\end{array}$ \\
\hline B5042 & $\begin{array}{l}\text { None } \\
\text { EXT } \\
\text { VI } \\
\text { DRO }\end{array}$ & $\begin{array}{r}18 \\
28 \\
110 \\
76\end{array}$ & $\begin{array}{l}160 \\
186 \\
176 \\
170\end{array}$ & $\begin{array}{l}189 \\
228 \\
214 \\
184\end{array}$ & $\begin{array}{r}23 \\
48 \\
164 \\
114\end{array}$ & $\begin{array}{l}89 \% \\
84 \% \\
59 \% \\
65 \%\end{array}$ & $\begin{array}{r}24 \\
37 \\
9 \\
12\end{array}$ \\
\hline B375 & $\begin{array}{l}\text { None } \\
\text { EXT } \\
\text { VI } \\
\text { DRO }\end{array}$ & $\begin{array}{l}25 \\
10 \\
32 \\
98\end{array}$ & $\begin{array}{l}215 \\
190 \\
248 \\
258\end{array}$ & $\begin{array}{l}207 \\
222 \\
204 \\
218\end{array}$ & $\begin{array}{r}19 \\
14 \\
118 \\
84\end{array}$ & $\begin{array}{l}91 \% \\
94 \% \\
75 \% \\
72 \%\end{array}$ & $\begin{array}{l}77 \\
88 \\
50 \\
53\end{array}$ \\
\hline
\end{tabular}

Note-Food sample stimulus is denoted by $F$, no-food samples by $N F$, red and green keylight comparison stimuli by $R$ and $G$, respectively, and reinforced and nonreinforced trials by $(+)$ and $(-)$.

no-food sample and began pecking immediately when the houselight came back on. The birds paused briefly after the food sample prior to beginning to peck the matching key. Discrimination ratios well above $80 \%$ were maintained on the DMTS task (Bird 346, 88.0\%; Bird 5042, $87.0 \%$; and Bird $375,86.0 \%$ ). These data are based on the five sessions prior to beginning the test phase.

\section{Probe Testing}

The top portion of Figure 2 shows baseline matching accuracy and test matching accuracy as a function of the interpolated stimuli. The EXT-associated stimulus did not reduce matching accuracy from baseline $[\mathrm{F}(1,16)=0.44$, n.s.]. The VI-associated stimulus did reduce matching accuracy from baseline $[F(1,16)=39.38, p<.05]$. These results replicate the findings of Experiment 1 . The new finding here is that the DRO-associated stimulus also reduced matching accuracy relative to baseline $[F(1,16)$ $=18.7, \mathrm{p}<.05]$.

Table 2 shows the mean rate of response during the test stimuli of the matching task as a function of test condition. The baseline data are averaged over the nine test sessions and the test data are averaged over the three test sessions of each test type, VI, EXT, DRO. Generally, these data show that the VI-associated and DRO-associated stimuli reduced matching accuracy by increasing the rate at which the birds pecked the nonmatching test stimuli. Bird 346 was disrupted across all test conditions, EXT, VI, and DRO. Birds 5042 and 375 were only slightly disrupted in the EXT condition. Table 2 also shows the discrimination ratios and delay-interval keypeck rate across these test conditions. These data show that whenever the interpolated stimulus reduced delay-interval responding on the matching key, matching accuracy declined. The one apparent exception is in the EXT condition for Bird 346. Individual test data (not shown in Table 2) indicated that this bird performed poorly on the first two EXT test sessions but at $90 \%$ on the third test session, and that delay-interval keypecks were reduced relative to 
baseline in the first two test sessions but not in the third. Thus, the averaged data shown in Table 2 for Bird 346 is the resalt of the combination of early disruption and later good performance. The individual sessions data for Bird 346 are consistent with the performance of the other birds, suggesting that disruption of baseline delay behavior is the critical variable responsible for retroactive interference in pigeon short-term memory.

During the probe test trials, all birds pecked the VIassociated stimulus at higher rates than they did the EXTassociated stimulus or the DRO-associated stimulus. Mean rates were $43,0.0$, and 4.2 pecks $/ \mathrm{min}$, respectively. Since both the VI- and DRO-associated stimulus occasioned high rates of responding, the rate of pecking the stimulus associated with the VI schedule is unlikely to be the variable controlling the degree of retroactive interference. This, too, suggests that disruption of baseline delay behavior is the source of retroactive interference, rather than responding to the interpolated stimuli per se.

During baseline training on the matching task, all birds pecked the right response key (the one upon which the stimuli of the matching task were presented) during the delays, and the rate after food was 27.2 pecks $/ \mathrm{min}$ and after no food was $49.8 \mathrm{pecks} / \mathrm{min}$. Sample-specific delay rates were analyzed separately according to the test condition. Baseline measures from the EXT test condition and the VI test condition revealed that the sample-specific rates were significantly different; the rate after the food sample was lower than the rate after the no-food sample [EXT, $\mathrm{F}(1,16)=8.18, \mathrm{p}<.05 ; \mathrm{VI}, \mathrm{F}(1,16)=5.18, \mathrm{p}<.05]$. However, during the baseline measures of the DRO test condition, delay rates did not differ [DRO, $F(1,16)=$ 3.68 , n.s.]. During testing, when the alternate side key was illuminated with an interpolated stimulus, the rates of responding after food and no-food sample stimuli on the dark response key (the one upon which the stimuli of the matching task were presented) did not significantly differ $[F(1,16)=.09$, n.s.; VI $F(1,16)=2.90$, n.s.; DRO, $F(1,16)=1.81$, n.s.]. Thus, sample-specific delay responding was eliminated by the interpolated stimulus, whether the birds pecked the stimulus or not.

The bottom portion of Figure 2 shows the rate of responding on the right key (the DMTS key) during baseline trials and probe trials of test sessions. As shown, delay rates did not differ between baseline trials and test trials when the EXT-associated stimulus was presented $[\mathrm{F}(1,16)=0.01, \mathrm{p}>.05]$. Delay rates differed between baseline and VI-associated stimulus $[F(1,16)=7.08$, $\mathrm{p}<.05]$ and between baseline and DRP-associated stimulus $[F(1,16)=6.67, p<.05]$. These data correspond perfectly with the matching data. When delayinterval behavior is altered, relative to baseline delay-behavior, matching accuracy declines. This relationship between behavioral disruption and matching accuracy is further supported by the high positive correlation between discrimination ratios and rate of delay keypecking (on the matching task key) during test conditions $[\mathrm{r}(27)=.490$, $\mathrm{p}<.01]$. Thus accurate matching is correlated with high rates of pecking (typical baseline rates) the response key associated with the matching task.

\section{Discussion}

The present results demonstrate once again that a stimulus associated with an EXT schedule does not retroactively interfere with delayed matching, and that a stimulus associated with a VI schedule does interfere with delayed matching. Additionally, Experiment 2 shows that a stimulus associated with a DRO schedule also interferes. Analysis of delay behavior during interpolated stimuli and baseline trials without interpolated stimuli suggests that retroactive interference of matching is correlated with the degree of disruption of baseline delay behavior produced by the interpolated stimuli. That the high rate of responding occasioned by the VI-associated stimulus is not a likely source of retroactive interference is demonstrated by the poor matching on trials with the DRO-associated stimulus interpolated. The DRO-associated stimulus did not occasion a high rate of response, but reduced matching accuracy relative to baseline. Perhaps the VI- and DRO-associated stimuli generated expectancies for food reinforcement and these expectancies interfered with accurate matching by increasing rate of responding during negative test stimuli. However, it then seems reasonable to assume that an EXT-associated stimulus generates an expectancy for nonreinforcement and thus reduces response rates during the positive test stimuli. But this did not occur. It is thus unlikely that expectancies for food reinforcement and nonreinforcement were the interfering agents. The more likely source of retroactive interference is disruption of delay behavior. Both the VI- and DROassociated stimuli disrupted delay behavior relative to baseline and disrupted matching accuracy; the EXTassociated stimulus did not disrupt delay behavior and did not disrupt matching.

\section{EXPERIMENT 3}

The purpose of this third experiment was to further replicate the findings of Experiments 1 and 2, and to extend the generality of the behavioral-disruption hypothesis of retroactive interference from food and no-food sample stimuli to the more conventional task in which the sample stimuli are keylights. The question of concern is whether the retroactive interference obtained in the previous two experiments is specific to the case of food and no-food sample stimuli and interpolated stimuli associated with the availability of food.

\section{Method}

\section{Subjects}

Five experimentally naive White Carneaux pigeons maintained under the same conditions in Experiment 1 were used as subjects.

\section{Apparatus}

The apparatus consisted of a TRS-80 Model III microcomputer 
interfaced via Alpha Products modules to the Lehigh Valley Electronics pigeon operant chamber described for Experiment 1 .

\section{Procedure}

The procedures of this experiment were identical to those of Experiment 2, except that terminal delay intervals in the delayed matching task were $4 \mathrm{sec}$ and sample stimuli were red and green keylight stimuli, the same as the test stimuli. Sample stimulus durations were 10 sec.

\section{Results}

\section{Acquisition}

One bird, DT1, failed to maintain reliable and accurate matching performance and was therefore not tested in the final phase of the experiment. Four birds successfully completed the experiment.

All four birds rapidly acquired the MULT VI EXT DRO discrimination and the delayed matching task. Mean response rates during the stimuli associated with the VI, EXT, and DRO components across the five sessions prior to testing were relatively high during the VI component $($ mean $=83.8 / \mathrm{min})$ and low during the EXT (mean $=$ $0.48 / \mathrm{min}$ ) and DRO (mean $=4.05 / \mathrm{min}$ ) components.

Generally, there was little difference in delay rates of responding after the red and green sample stimuli of the DMTS task; two birds responded at somewhat higher rates following the green sample stimulus (DT3-after green, $203.8 \mathrm{pecks} / \mathrm{min}$, after red, 188.2 pecks $/ \mathrm{min}$; DT4-after green, 264.2 pecks/min, after red, 233.1 pecks $/ \mathrm{min}$ ) and two birds responded at somewhat higher rates following the red sample (DT2-after red, 181.9 pecks/min, after green 66.4 pecks $/ \mathrm{min}$ ). All birds remained at the response key during the delays of the matching task. Other than the slight differences in response rates, no sample-specific behavior was observed. Discrimination ratios were all maintained above $80 \%$ (DT2, 88.8\%; DT3, 83.6\%; DT4, $85.2 \%$; DT5, $87.8 \%$ ). These data are based on the five sessions prior to testing.

\section{Probe Testing}

The top portion of Figure 3 compares baseline matching accuracy with test matching accuracy as a function of the interpolated stimulus condition. The EXTassociated stimulus reduced matching accuracy from $80 \%$ to $70 \%$ when interpolated into delays, but this difference is not statistically significant $[F(1,22)=4.81, n . s$.$] . The$ VI-associated stimulus reduced matching accuracy relative to baseline $[F(1,22)=14.64, p<.05]$. These results are consistent with the previous experiments. However, inconsistent with previous results, the DRO-associated stimulus failed to significantly reduce matching accuracy relative to baseline accuracy $[\mathrm{F}(1,22)=1.69$, n.s.].

Table 3 shows the mean rates of responding during test stimuli discrimination ratios, and delay-interval keypecks for each bird individually and as a function of the interpolated test conditions. The results show a high degree of variability across subjects; DT4 was almost completely disrupted by all interpolated stimuli, DT5 shows interference with matching by both the DRO- and VI-

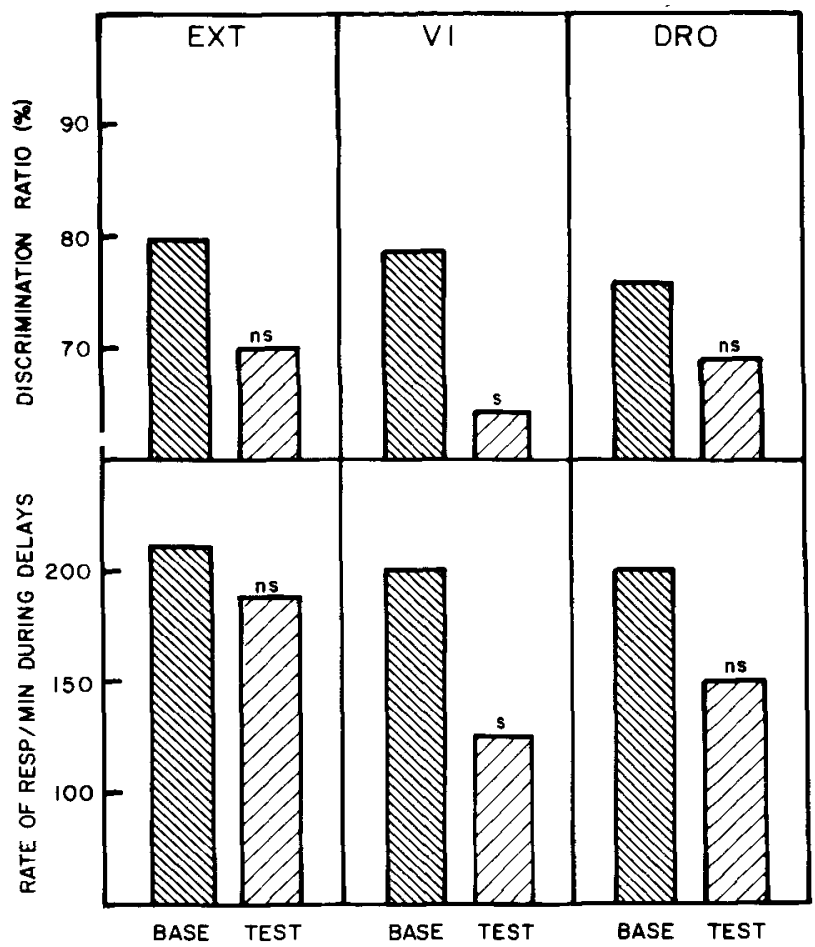

Figure 3. The top portion shows matching accuracies as a function of three test conditions: delays filled with stimuli associated with extinction (EXT), variable interval schedule (VI), and a differential reinforcement of other behavior schedule (DRO). The bottom portion shows mean rates of responding during delay intervals as a function of the three test conditions. No stimuli were presented during delays of baseline trials. These data are from Experiment 3. Nonsignificant (ns) and significant (s) differences from baseline are noted.

associated stimuli, and DT3 was apparently disrupted by interpolation of the EXT-associated stimulus. The VIassociated stimulus consistently reduced matching accuracy relative to baseline in all subjects.

Generally, the VI-associated stimulus reduced matching accuracy by increasing response rates during negative test stimuli, rather than reducing rates during positive test stimuli. Indeed, rates during positive test stimuli were remarkably consistent across all conditions (baseline, 178/min; EXT, 175/min; VI, $182 / \mathrm{min}$; DRO, $175 / \mathrm{min}$ ). Response rates during negative test stimuli were $59 / \mathrm{min}$ on baseline trials, $85 / \mathrm{min}$ on EXT trials, $112 / \mathrm{min}$ on VI trials, and $90 / \mathrm{min}$ on DRO trials.

Mean response rates on the right key during the interpolated stimuli were: $46.9 / \mathrm{min}$ during the VI-associated stimulus, $0.5 / \mathrm{min}$ during the EXT-associated stimulus, and $5.9 / \mathrm{min}$ during the DRO-associated stimulus. Generally, these means accurately reflect the individual bird's performance, although DT2 pecked the VI-associated stimulus at a rate of $99.1 / \mathrm{min}$ and DT4 pecked the DROassociated stimulus at a mean rate of $15.9 / \mathrm{min}$.

The bottom portion of Figure 3 shows baseline and test delay-interval response rates on the dark matching key. Consistent with the results of Experiment 2, no differ- 
Table 3

Mean Response Rates per Minute During the Comparison Stimuli of the Delayed Matching Task in Experiment 3

\begin{tabular}{|c|c|c|c|c|c|c|c|}
\hline \multirow{2}{*}{ Subjects } & \multirow{2}{*}{$\begin{array}{l}\text { Delay } \\
\text { Stimulus }\end{array}$} & \multicolumn{4}{|c|}{ Trial Types } & \multirow{2}{*}{$\begin{array}{c}\text { Discrimination } \\
\text { Ratio }\end{array}$} & \multirow{2}{*}{$\begin{array}{c}\text { Delay } \\
\text { Keypecks }\end{array}$} \\
\hline & & RG- & GG+ & RR+ & GR- & & \\
\hline DT4 & $\begin{array}{l}\text { None } \\
\text { EXT } \\
\text { VI } \\
\text { DRO }\end{array}$ & $\begin{array}{l}142 \\
196 \\
188 \\
188\end{array}$ & $\begin{array}{l}228 \\
238 \\
222 \\
229\end{array}$ & $\begin{array}{l}142 \\
196 \\
188 \\
188\end{array}$ & $\begin{array}{l}118 \\
180 \\
194 \\
205\end{array}$ & $\begin{array}{l}65 \% \\
56 \% \\
55 \% \\
54 \%\end{array}$ & $\begin{array}{l}246 \\
264 \\
177 \\
142\end{array}$ \\
\hline DT2 & $\begin{array}{l}\text { None } \\
\text { EXT } \\
\text { VI } \\
\text { DRO }\end{array}$ & $\begin{array}{r}39 \\
43 \\
123 \\
62\end{array}$ & $\begin{array}{l}177 \\
180 \\
189 \\
180\end{array}$ & $\begin{array}{l}181 \\
173 \\
177 \\
143\end{array}$ & $\begin{array}{l}26 \\
52 \\
89 \\
48\end{array}$ & $\begin{array}{l}85 \% \\
79 \% \\
63 \% \\
75 \%\end{array}$ & $\begin{array}{l}174 \\
230 \\
105 \\
180\end{array}$ \\
\hline DT5 & $\begin{array}{l}\text { None } \\
\text { EXT } \\
\text { VI } \\
\text { DRO }\end{array}$ & $\begin{array}{l}29 \\
51 \\
76 \\
63\end{array}$ & $\begin{array}{l}127 \\
123 \\
132 \\
130\end{array}$ & $\begin{array}{l}119 \\
119 \\
146 \\
127\end{array}$ & $\begin{array}{l}32 \\
18 \\
92 \\
76\end{array}$ & $\begin{array}{l}80 \% \\
78 \% \\
62 \% \\
65 \%\end{array}$ & $\begin{array}{l}83 \\
75 \\
65 \\
62\end{array}$ \\
\hline DT3 & $\begin{array}{l}\text { None } \\
\text { EXT } \\
\text { VI } \\
\text { DRO }\end{array}$ & $\begin{array}{l}44 \\
88 \\
52 \\
38\end{array}$ & $\begin{array}{l}155 \\
144 \\
174 \\
165\end{array}$ & $\begin{array}{l}186 \\
162 \\
178 \\
188\end{array}$ & $\begin{array}{l}44 \\
54 \\
81 \\
36\end{array}$ & $\begin{array}{l}79 \% \\
68 \% \\
72 \% \\
83 \%\end{array}$ & $\begin{array}{l}174 \\
200 \\
180 \\
211\end{array}$ \\
\hline
\end{tabular}

Note - Red and green comparison stimuli are denoted by $R$ and $G$, respectively. Reinforced and nonreinforced trials are denoted by $(+)$ and $(-)$

ence was observed in the EXT condition $[F(1,22)=.34$, n.s.] between baseline and testing of delay-interval responding on the right key. That is, the EXT-associated stimulus did not reduce delay-interval responding and did not disrupt matching accuracy. A significant difference was observed between baseline responding and test responding during delays when the VI-associated stimulus was presented $[F(1,22)=4.82, p<.05]$. Thus, the $\mathrm{VI}$-associated stimulus reduced response rates relative to rates on the matching task key and disrupted matching accuracy.

The interesting finding is that delay-interval response rates did not differ in the DRO condition $[F(1,22)=2.59$, n.s.]. This is the expected result given that no disruption of matching accuracy was observed. These results are therefore exactly as predicted by our hypothesis that the amount of retroactive interference is a function of the extent to which the interpolated stimulus disrupts behavior associated with accurate matching. This relationship between disruption of baseline delay-interval response rates during interpolated stimuli and matching accuracy is further supported by the high positive correlation between discrimination ratios and rate of delay keypecking (on the matching task key) during test conditions $[\mathrm{r}(32)=.442$, $p<.01]$. Thus, once again, accurate matching is correlated with high rates (typical baseline rates) of responding on the response key associated with the matching task.

\section{Discussion}

Experiment 3 demonstrated that when the pigeons maintained baseline delay behavior, matching accuracy was good; when baseline delay behavior was disrupted by the interpolated stimuli, as evidenced by decreased delay response rates, matching accuracy was poor. The failure of the DRO-associated stimulus to reduce the rate of baseline delay responding was correlated with its failure to interfere with delay matching. It is possible that the shorter delay durations in this experiment than in Experiment 2 are responsible for the increased subject variability and for the difference in the function of the DRO-associated stimulus. The DRO schedule may have gained control of behavior, but there may not have been enough time for it to disrupt delay behavior. It is also possible that the color matching task makes greater demands on memory processing than the food/no-food matching task, which may account for the increased subject variability and for the generally lower baseline performance during test sessions of Experiment 3 relative to Experiment 2. Interference is more difficult to detect with low baseline matching accuracy.

\section{GENERAL DISCUSSION}

The present results show that a stimulus associated with an EXT schedule does not retroactively interfere with delayed matching when presented during delay intervals, but that a stimulus associated with a VI schedule of reinforcement does interfere with delayed matching when presented during delay intervals. A stimulus associated with a DRO schedule interfered with delayed matching in Experiment 2 but not in Experiment 3. The high rate of responding occasioned by the VI schedule may be a sufficient source of interference, but it is not necessary. The DRO- and VI-associated stimuli may have generated expectancies for food reinforcement that interfered with matching accuracy, perhaps by increasing rate of responding during the nonmatching test stimuli. However, there is no evidence that the EXT-associated stimulus decreased rate of responding during the matching test stimuli. One would expect the EXT-associated stimulus to generate an expectancy for nonreinforcement, reduce response rates, and retroactively interfere with delayed matching if the expectancies were responsible for interference.

The current experiments do demonstrate that retroactive interference was obtained whenever baseline delay behavior was disrupted. The VI-associated stimulus disrupted baseline delay behavior and interfered with delayed matching; the EXT-associated stimulus did neither. The DRO-associated stimulus disrupted baseline delay behavior in Experiment 2 and interfered with matching, but did not disrupt baseline delay behavior in Experiment 3 and did not interfere.

These results provide little evidence that retroactive interference is a result of disruption of sample-specific mediating behavior (Thompson et al., 1983; Urcuioli \& Honig, 1980; Zentall et al., 1978). In Experiment 1, one bird exhibited sample-specific delay-interval responding and one bird did not; retroactive interference was observed in both birds. In Experiment 2, although sample-specific delay behavior was observed and eliminated across all test conditions, including the EXT condition, retroactive interference was found in only the VI and DRO conditions. 
In Experiment 3, sample-specific delay behavior was not observed, and yet retroactive interference was obtained. Sample-specific behavior can be difficult to observe, and it is possible that we simply failed to observe it in these experiments. The behavior may have been more covert than overt, as when one moves one's tongue or focuses on near and then far objects in the same visual space.

Thompson et al. (1983) have argued for a dual rehearsal process with an overt mediational component and a covert mediational component. They argue that covert rehearsal, that is, sample-specific mediating behavior, is the memory trace, not merely a correlate. Covert rehearsal, they argue, mediates delays in a manner analogous to overt rehearsal, and accounts for cases in which sample-specific mediating behavior is not present. They would thus account for our results in terms of disruption of covert rehearsal. The problem with this account is that it fails to consider the relationship between disruption of baseline delay behavior that is not sample-specific and retroactive interference. Why should disruption of delay behavior that is not sample-specific interfere with delayed matching? What role in short-term memory can be served by such delay behavior?

Kendrick et al. (1981) proposed that response-produced stimuli arising from delay behavior serve as a context supporting retrieval of sample stimulus information. We proposed that delay behavior is the context in which sample information is maintained via cover rehearsal. As long as this behavior is maintained, the information necessary to perform delayed matching is maintained. Delay behavior may be maintained throughout the delay or, once disrupted, may be reinstated at the end of the delay interval. Maintenance and reinstatement of baseline delay behavior both result in accurate matching. The present results and those of Thompson et al. (1983) are consistent with this behavioral-context hypothesis.

However, Thompson et al. have argued that their dual coding hypothesis, which assumes that animals overtly rehearse instructions to peck and not to peck and at the same time covertly rehearse what test stimulus to peck at, is a more parsimonious explanation. We think not. Context-dependent retrieval has wide acceptance in the animal long-term memory literature (e.g., D'Amato \& Worsham, 1974; Gordon, 1981; Honig \& Thompson, 1982; Spear, 1981), and is invoked to explain learning in nearly all experimental preparations, including serial probe recognition, radial arm maze performance, autoshaping, classical conditioning, aversive conditioning, etc. (Bouton \& Bolles, 1979; Olton, 1978; Tomie, 1976; Wagner, 1978). Recent investigations of human and animal short-term memory have indicated contextdependent retrieval in directed forgetting (Bjork \& Geiselman, 1978; Kendrick et al., 1981; Stonebraker et al., 1981). Furthermore, a two-stores account of human memory with two operating processes, one for long-term memories and one for short-term memories, is no longer seriously accepted (Anderson, 1982; Lewis, 1979; Murdock 1982; Raaijmakers \& Shiffrin, 1981). Our context hypothesis does not require a two-stores view of animal memory (see Kendrick \& Rilling, in press, for details).

The present data, and all available data, are consistent with the idea that disruption of baseline delay behavior may disrupt overt and covert rehearsal and alters the context necessary for test stimuli to effect retrieval of sample stimulus information. In view of the wealth of data within and beyond the animal learning literature supporting context-dependent retrieval processes, we conclude that our behavioral-context hypothesis is the most parsimonious explanation of retroactive interference effects in animal short-term memory preparations.

\section{REFERENCES}

Anderson, C. M. B., \& Craik, F. I. M. (1974). The effect of a concurrent task on recall from primary memory. Journal of Verbal Learning and Verbal Behavior, 13, 107-113.

ANDERSON, J. R. (1982). Acquisition of cognitive skill. Psychological Review, 89, 369-406.

Bjork, R. A., \& Geiselman, R. E. (1978). Constituent processes in the differentiation of items in memory. Journal of Experimental Psychology: Human Learning and Memory, 4, 347-361.

Blough, D. S. (1959). Delayed matching in the pigeon. Journal of the Experimental Analysis of Behavior, 2, 151-160.

Bouton, M. E., \& BolLes, R. C. (1979). Role of conditioned contextual stimuli in the reinstatement of extinguished fear. Journal of Experimental Psychology: Animal Behavior Processes, 5, 368-378.

Cook, R. G. (1980). Retroactive interference in pigeon short-term memory by a reduction in ambient illumination. Journal of Experimental Psychology: Animal Behavior Processes, 6, 326-338.

D'Amato, M. R., \& WorshaM, R. W. (1974). Retrieval cues and shortterm memory in capuchin monkeys. Joumal of Comparative and Physiological Psychology, 86, 274-282.

Delong, R. E., \& Wasserman, E. A. (1981). Effects of differential reinforcement expectancy on successive matching-to-sample performance in pigeons. Journal of Experimental Psychology: Animal Behavior Processes, 1, 394-412.

GORDON, W. C. (1981). Mechanisms for cue-induced retention enhancement. In N. E. Spear \& R. R. Miller (Eds.), Information processing in animals: Memory mechanisms. Hillsdale, NJ: Erlbaum.

GRANT, D. S., \& RoBERTS, W. A. (1976). Sources of retroactive inhibition in pigeon short-term memory. Journal of Experimental Psychology: Animal Behavior Processes, 2, 1-16.

Honig, W. K., \& Thompson, R. K. R. (1982). Retrospective and prospective processing in animal working memory. In G. Bower (Ed.), The psychology of learning and motivation, 16, 239-283.

KENDRICK, D. F., \& RiLling, M. (in press). AIM: A theory of active and inactive memory. In D. F. Kendrick, M. Rilling, \& M. R. Denny (Eds.), Theories of animal memory. New York: Erlbaum.

Kendrick, D. F., Rulung, M., \& Stonebraker, T. B. (1981). Stimulus control of delayed matching in pigeons: Directed forgetting. Journal of the Experimental Analysis of Behavior, 36, 241-251.

KULP, R. A. (1967). Effects of amount of interpolated activity in shortterm memory. Psychological Reports, 21, 393-399.

LEWIS, D. J. (1979). Psychobiology of active and inactive memory Psychological Bulletin, 86, 1054-1083.

MAKI, W. S. (1979). Discrimination learning without short-term memory: Dissociation of memory processes in pigeons. Science, 204, 83-85.

MAKI, W. S., \& HEGVIK, D. K. (1980). Directed forgetting in pigeons. Animal Learning \& Behavior, 8, 576-575.

Medin, D. L., Reynolds, T. J., \& Parkinson, J. K. (1980). Stimulus similarity and retroactive interference and facilitation in monkey short-term memory. Journal of Experimental Psychology: Animal Behavior Processes, 6, 112-125. 
MoIse, S. L. (1970). Short-term retention in Macaca speciosa following interpolated activity during delayed matching from sample. Journal of Comparative and Physiological Psychology, 73, 506-514.

MuRdock, B. B., JR. (1967). Distractor and probe techniques in shortterm memory. Canadian Journal of Psychology, 21, 25-36.

MURDock, B. B., JR. (1982). A theory for the storage and retrieval of item and associative information. Psychological Review, 89, 609-626.

OLtoN, D. S. (1978). Characteristics of spatial memory. In S. H. Hulse, H. Fowler, \& W. K. Honig (Eds.), Cognitive processes in animal behavior. Hillsdale, NJ: Erlbaum.

Peterson, G. B., \& Trapold, M. A. (1980). Effects of altering outcome expectancies on pigeons delayed conditional discrimination performance. Learning and Motivation, 11, 267-288.

POSNER, M. I., \& KoNICK, A. F. (1966). Short-term retention of visual and kinesthetic information. Organizational Behavior and Human Performance, 1, 71-86.

PYLYSHYN, Z. W. (1965). The effect of a brief interpolated task on shortterm retention. Canadian Journal of Psychology, 19, 280-287.

RaAiJmakers, J. G. W., \& Shiffrin, R. M. (1981). Search of associative memory. Psychological Review, 88, 93-134.

RoBerts, W. A., \& GRANT, P. S. (1978). An analysis of light induced retroactive inhibition in pigeon short-term memory. Journal of Experimental Psychology: Animal Behavior Processes, 4, 219-236.

SPEAR, N. E. (1981). Extending the domain memory retrieval. In N. E. Spear \& R. R. Miller (Eds.), Information processing in animals: Memory mechanisms. Hillsdale, NJ: Erlbaum.

Stonebraker, T. B., Rilling, M., \& Kendrick, D. F. (1981). Time dependent effects of double cuing in directed forgetting. Animal Learning \& Behavior, 9, 305-394.

Thompson, R. K. R., Van Hemel, P. E., Winston, K. M., \& Pappas, N. (1983). Modality-specific interference with overt mediation by pigeons in a delayed discrimination task. Learning and Motivation, 14, 271-303.
TоміE, А. (1976). Interference with autoshaping by prior context conditioning. Journal of Experimental Psychology: Animal Behavior Processes, 2, 323-334.

Tranberg, D. K., \& Rilling, M. (1980). Delay interval illumination changes interfere with pigeon short-term memory. Journal of the Experimental Analysis of Behavior, 33, 39-49.

URCUIOLI, P. J., \& HonIG, W. K. (1980). Control of choice in conditional discriminations by sample-specific behaviors. Journal of $E x$ perimental Psychology: Animal Behavior Processes, 6, 207-219.

WAGNER, A. R. (1978). Expectancies and the priming of STM. In S H. Hulse, H. Fowler, \& W. K. Honig (Eds.), Cognitive processes in animal behavior. Hillsdale, NJ: Erlbaum.

WASSERMAN, E. A. (1976). Successive matching-to-sample in the pigeon: Variations on a theme by Kornorski. Behavior Research Methods \& Instrumentation, 8, 278-282.

WILKIE, D. M., Summers, R. J., \& SPETCh, M. L. (1981). Effect of delay-interval stimuli on delayed symbolic matching to sample in the pigeon. Journal of the Experimental Analysis of Behavior, 35, 153-160.

Williams, H. L., Beaver, W. S., Spence, M. T., \& Rundell, O. H. (1969). Digital and kinesthetic memory with interpolated information processing. Journal of Experimental Psychology, 80, 530-536.

Wright, A. A., Urcuioli, P. J., Sands, S. F., \& Santiago, H. C. (1981). Interference of delayed matching to sample in pigeons: Ef fects of interpolation at different periods within a trial and stimulus similarity. Animal Learning \& Behavior, 9, 595-603.

Zentall, T. R., Hogan, P. E., Howard, M. M., \& Moore, B. S. (1978). Delayed matching in the pigeon: Effect on performance of sample-specific observing responses and differential delay behavior. Learning and Motivation, 9, 202-218.

(Manuscript received February 8, 1984; revision accepted for publication July 26,1984 .) 